\title{
Kajian Potensi Cadangan Airtanah di Area Kampus Universitas Muhammadiyah Purwokerto Menggunakan Metode Geolistrik
}

\section{Study of the Potential of Groundwater Reserves in Campus Area of Universitas Muhammadiyah Purwokerto Using Geoelectric Method}

\author{
Suwarsito $^{1}$, Radin Alhif Dirgantara ${ }^{2}$, dan Esti Sarjanti ${ }^{3}$ \\ 1,2,3)Program Studi Pendidikan Geografi, Fakultas Keguruan dan Ilmu Kependidikan \\ Universitas Muhammadiyah Purwokerto \\ Jl. K.H. Ahmad Dahlan, Kembaran, Purwokerto, 53182, Indonesia. \\ email: ${ }^{1}$ suwarsito.ito@ump.ac.id, ${ }^{2}$ radinalhifdirgantara@gmail.com, ${ }^{3}$ esti.sargeo@gmail.com
}

\begin{abstract}
ABSTRAK
DOI;

10.30595/jrst.v5i1.8487

Histori Artikel:

Diajukan:

03/09/2020

Diterima:

$07 / 12 / 2020$

Diterbitkan:

03/03/2021

Tujuan penelitian ini adalah untuk menganalisis potensi cadangan air tanah di kawasan kampus utama Universitas Muhammadiyah Purwokerto (UMP). Metode penelitian menggunakan metode observasi. Data penelitian ini meliputi tahanan jenis (resistivitas), ketebalan akuifer dan cadangan air tanah. Pengumpulan data menggunakan aplikasi metode geolistrik konfigurasi Wenner-Schlumberger terdiri dari 2 lintasan. Pengolahan data dilakukan dengan menggunakan Microsoft Excel dan Res2dinv2D untuk mendapatkan penampang resistivitas 2D dan jenis lapisan tanah dengan ketebalannya. Analisis data menggunakan persamaan Darcy untuk memperoleh besarnya potensi cadangan air tanah yang berupa nilai debit air (Q). Hasil penelitian menunjukkan bahwa potensi cadangan airtanah di area kampus utama UMP sebesar $351,53 \mathrm{~m}^{3} /$ hari atau 4,07 liter/detik. Menurut Keputusan Menteri ESDM No.1451 K/10/ MEM/2000, potensi cadangan airtanah di kampus utama UMP termasuk dalam kriteria "sedang".
\end{abstract}

Kata Kunci: Cadangan Air Tanah, Metode Geolistrik, Persamaan Darcy.

\begin{abstract}
The study was purposed to analyze the potential for groundwater reserves in the main campus area of Universitas Muhammadiyah Purwokerto (UMP). The research uses observation method. The data of the study include resistivity, thickness of aquifers and groundwater reserves. Data collection using the geoelectric method application Wenner-Schlumberger configuration consists of 2 lines. Data processing was performed using Microsoft Excel and Res2dinv2D to obtain a 2D resistivity cross section and the type of soil layer with its thickness. Data analysis uses the Darcy equation to obtain the potential amount of groundwater reserves in the form of water discharge (Q). The results showed that the potential for groundwater reserves in the main campus area of UMP was $351.53 \mathrm{~m}^{3} /$ day or 4.07 liters/second. According to the Decree of the Minister of Energy and Mineral Resources No.1451 K / 10 / MEM / 2000, the potential for groundwater reserves in the main campus area of UMP was included in the "medium" criteria.
\end{abstract}

Keywords: Groundwater Reserves, Geoelectric Method, Darcy Equation 


\section{PENDAHULUAN}

Perubahan tata guna lahan dapat mempengaruhi ketersediaan airtanah baik secara kuantitas maupun kualitas. Secara alami, airtanah mengandung unsur-unsur kimia dalam jumlah tertentu yang berasal dari air hujan melalui proses infiltrasi ke bawah permukaan tanah. Selain itu, karakteristik dan geometri akuifer tanah juga berpengaruh terhadap keberadaan airtanah pada suatu cekungan airtanah dan sebagai media yang menentukan arah aliran airtanah. Imbuhan airtanah pada akuifer sangat dipengaruhi oleh curah hujan, limpasan air permukaan, evapotranspirasi, rekayasa manusia, dan sistem aliran air permukaan (Karels, 2014). Distribusi hujan dan jumlah curah hujan yang diterima pada daerah tangkapan hujan merupakan salah satu penentu kuantitas airtanah yang berkorelasi dengan daerah imbuhan (recharge area) dan daerah tangkapan (catchment area) (Mareta, 2015).

Seiring perkembangan waktu, sumber daya air telah mengalami perubahan baik dari segi kualitas maupun kuantitas. Hal ini disebabkan oleh pertumbuhan penduduk dan adanya perubahan alam secara alami (Hatala, 2007). Pertumbuhan penduduk yang pesat di Indonesia dapat dilihat di beberapa wilayah kota berkembang, salah satunya adalah kawasan kampus Universitas Muhammadiyah Purwokerto (UMP) dan sekitarnya. Kawasan kampus utama UMP yang terletak di Desa Dukuhwaluh, Kecamatan Kembaran, Kabupaten Banyumas secara geologi merupakan daerah vulkanik purba hasil dari endapan Gunungapi Slamet. Secara lateral, sebaran batuan ini akan mengkontrol pola aliran airtanah di daerah tersebut.

UMP merupakan salah satu universitas swasta besar yang ada di Jawa Tengah bagian barat, mengalami perkembangan yang pesat. Perkembangan ini dapat dilihat dari semakin banyaknya properti seperti penambahan bangunan kampus untuk ruang perkuliahan, perkantoran, dan laboratorium. Selain itu, kawasan di sekitar kampus UMP juga semakin banyak berdiri bangunan untuk perumahan penduduk, warung makan, kios, rumah kostkostan dan lain-lain. Kebutuhan akan airtanah dari tahun ke tahun terus meningkat. Dampak yang terjadi adalah penurunan muka airtanah yang berada di kawasan kampus UMP dan sekitarnya. Penurunan ini diduga karena adanya ketidakseimbangan antara imbuhan airtanah (input) dengan pengambilan airtanah (output).
Pada saat musim kemarau, beberapa titik sumber air di area kampus UMP mengalami kekeringan, padahal sudah dilakukan upaya memperdalam sumber air sampai beberapa meter.

Berbagai penelitian telah dilakukan untuk mengetahui keberadaan dan potensi airtanah di berbagai wilayah di Indonesia. Penelitian Sumartoyo (2010) telah berhasil mengestimasi potensi airtanah melalui pendekatan tipologi bentuklahan Wilayah Bogor, Provinsi Jawa Barat. Penelitian Ashari et al., (2014) telah melakukan pemetaan penyebaran pola akuifer dengan metode resistivitas sounding konfigurasi Schlumberger di Daerah Dayu, Gondangrejo, Karanganyar. Lebih lanjut Prasetya et al., (2016) telah melakukan penelitian mengenai prediksi cadangan airtanah di Daerah Aliran Sungai (DAS) Cisadane. Penelitian Saputra et al., (2016) juga telah melakukan perhitungan potensi airtanah di Kecamatan Gabus Wetan, Kabupaten Indramayu, Jawa Barat. Sedangkan penelitian Putri et al., (2018) telah berhasil mengkaji sistem aliran dan potensi airtanah di sebagian Desa Sembangun ditinjau dari aspek kualitas dan kuantitasnya. Risanti et al., (2018) telah melakukan penelitian hidrostratigrafi akuifer dan estimasi potensi airtanah bebas guna mendukung kebutuhan air domestik Desa Sembungan. Maria et al., (2018) juga telah melakukan penelitian mengenai hidrogeologi dan potensi cadangan airtanah di dataran rendah Indramayu.

Informasi mengenai sumber daya air khususnya cadangan airtanah di kawasan kampus utama UMP di Desa Dukuhwaluh, Kecamatan Kembaran, Kabupaten Banyumas belum banyak diketahui. Oleh karena itu, penelitian ini dimaksudkan untuk menganalisis potensi cadangan airtanah di kawasan kampus utama Universitas Muhammadiyah Purwokerto yang terletak di Desa Dukuhwaluh, Kecamatan Kembaran, Kabupaten Banyumas.

\section{METODE PENELITIAN}

Penelitian ini menggunakan metode observasi lapangan. Metode observasi lapangan digunakan untuk memperoleh data primer di lapangan. Data penelitian meliputi tahanan jenis (resistivitas), ketebalan akuifer, dan cadangan airtanah.

Alat dan bahan yang digunakan dalam penelitian ini adalah alat ukur geolistrik yang terdri dari : (a) Geolistrik Earth Restivity Metre type SAZ 3000 G100, model BD 1000, Serial Number M422002 dengan impedansi sebesar 10 
Mohm, (b) seperangkat komputer yang dilengkapi software surfer 13, progress version 3 dan ArcGis 10 (c) 2 kabel unit sepanjang $500 \mathrm{~m}$ untuk elektroda arus, (d) 2 unit kabel sepanjang $30 \mathrm{~m}$ untuk elektoda potensial, (e) 1 unit AVO meter, (f) 2 unit palu, (5) GPS, (6) peta citra Google Earth 4.4.

Pengumpulan data menggunakan aplikasi metode geolistrik konfigurasi WennerSchlumberger terdiri dari 2 lintasan. Lintasan 1 memiliki panjang $195 \mathrm{~m}$ membujur dari utara ke selatan, sedangkan lintasan 2 memiliki panjang 195 m membujur dari barat ke timur kawasan kampus utama UMP. Penelitian ini dilakukan dengan cara mengalirkan arus listrik searah ke dalam tanah melalui dua buah electrode arus $\mathrm{A}$ dan B. Jarak antar elektroda geolistrik adalah 15 meter dengan arah penampangnya melintang dari arah barat hingga timur. Akibat adanya perbedaan jenis lapisan batuan yang dilalui arus tersebut, akan menimbulkan perbedaan potensial. Konfigurasi elektroda arus WennerSchlumberger ditunjukkan pada Gambar 1.

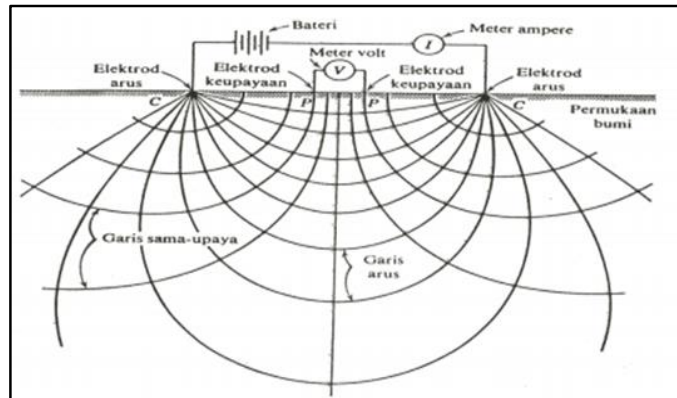

Gambar 1. Konfigurasi Elektroda Arus Wenner-Schlumberger (Flathe \& Leibold, 1976)

Pengolahan data dilakukan dengan menggunakan Microsoft Excel dan Res2dinv2D untuk mendapatkan penampang resistivitas 2D dan jenis lapisan tanah dengan ketebalannya. Ketebalan akuifer dapat dilihat berdasarkan besarnya tahanan jenis (resistivitas) setelah tahap pengolahan data di atas.

Analisis data menggunakan persamaan Darcy untuk memperoleh besarnya potensi cadangan airtanah yang berupa nilai debit air (Q). Perhitungan debit air (Q) ditunjukkan pada persamaan (1) (Todd and Mays, 2005).

$Q=K \times W \times$ bakuifer $\times \delta h / \delta l(1)$

$\mathrm{Q}=$ debit air (m3/hari)

$\mathrm{K}=$ Konduktivitas hidrolik (m/hari)

$\mathrm{W}=$ Panjang penampang akuifer $(\mathrm{m})$ bakuifer = ketebalan akuifer (m)

$\delta \mathrm{h}=$ Beda kedalaman muka airtanah (m)

$\delta \mathrm{l}=$ Panjang lintasan airtanah $(\mathrm{m})$

\section{HASIL DAN PEMBAHASAN}

Berdasarkan peta geologi regional lembar Purwokerto dan Tegal menunjukkan bahwa kondisi geologi di daerah penelitian adalah Aluvium (Qa) dan Endapan Lahar Gunung Slamet (Qls). Aluvium merupakan endapan bentuk sekunder hasil rombakan batuan di permukaan yang telah terbentuk sebelumnya. Endapan terdiri dari material lepas berupa lempung, pasir, bongkahan andesit basalt, granit, dan batugamping. Endapan lahar Gunung Slamet merupakan lahar dengan bongkahan batuan gunungapi bersusunan andesit-basal, bergaris tengah $10-50 \mathrm{~cm}$. Endapan lahar ini dihasilkan oleh Gunung Slamet tua yang sebarannya meliputi daerah datar. Berdasarkan tingkat konsolidasinya, batuan di daerah penelitian dikelompokkan menjadi batuan padu dan batuan lepas atau setengah padu.

Data yang diperoleh dari hasil pengukuran secara real di lapangan berupa kuat arus listrik (V) dan beda potensial (I) pada lintasan 1 dan lintasan 2, selanjutnya dihitung nilai resistivitas semunya. Besarnya nilai resistivitas dikelompokkan sesuai dengan kedalaman lapisan. Berdasarkan besaran nilai resistivitas menggunakan klasifikasi menurut Telford et al., (1990), dapat diketahui tipe batuannya seperti terlihat pada Tabel 1.

Tabel 1. Nilai resistivias setiap tipe batuan

\begin{tabular}{ll}
\hline Material & Resistivitas $(\Omega \mathrm{m})$ \\
\hline Kwarsa (Quartz) & $500-8 \times 10^{5}$ \\
Kalsit (Calsite) & $10^{12}-10^{13}$ \\
Granit & $200-10^{5}$ \\
Andesit (Andesite) & $1.7 \times 10^{2}-45 \times 10^{4}$ \\
Gamping (Limestone) & $500-10^{4}$ \\
Batu Pasir (Sandstone) & $200-8.000$ \\
Pasir (Sand) & $1-1.000$ \\
Lempung (Clay) & $1-100$ \\
Kerikil Kering (Dry & $600-10^{3}$ \\
Gravel) & $10-800$ \\
Aluvium (Alluvium) & $100-600$ \\
Kerikil (Gravel) &
\end{tabular}

Hasil pengukuran menggunakan metode geolistrik konfigurasi Wenner-Schlumberger, diperoleh berbagai macam lapisan batuan. 
Dengan melakukan inversi menggunakan software res2dinv2D, dihasilkan penampang dua dimensi. Dari penampang dua dimensi tersebut, kemudian dilakukan penafsiran jenis lapisan batuan penyusun pada setiap titik pengukuran berdasarkan sebaran kesamaan nilai resistivitasnya.

Hasil penelitian menggunakan Geolistrik diperoleh gambar penampang akuifer di kawasan kampus utama UMP baik pada lintasan 1 (L1) maupun lintasan 2 (L2) (Gambar 2).

Lintasan 1 diambil di kawasan UMP membentang mulai dari timur ke barat sepanjang 195 m dengan kedalaman 39,2 m. Pada lintasan 1 ini memiliki elevasi sekitar $3 \%$. Lintasan 1 terletak pada koordinat $7^{\circ} 24^{\prime} 48.13^{\prime \prime}$ LS dan $109^{\circ} 16^{\prime} 28^{\prime \prime}$ BT; serta ketinggian 101 meter di atas permukaan laut (mdpl). Penampang dan nilai resistivitas dua dimensi lintasan 1 disajikan pada Gambar 3.

Berdasarkan Gambar 3, lapisan berwarna biru tua hingga biru muda diinterpretasikan sebagai lapisan airtanah dengan nilai resistivitas antara 1,25 - 5,67 $\Omega \mathrm{m}$. Kedalaman akuifer bebas diperkirakan terletak pada kedalaman 1,88 - 32,3 $\mathrm{m}$ bawah muka tanah (bmt). Kedalaman sumur di sekitar lintasan 1 berkisar antara $10-12 \mathrm{~m}$. Hasil interpretasi penampang dua dimensi lintasan 1 al. (1990), jenis material yang terdapat pada Lintasan 1 terdiri dari pasir, lempung, dan batu pasir (Tabel 2).

Tabel 2. Nilai Resistivitas Material Lintasan 1

\begin{tabular}{cl}
\hline Nilai Resistivitas $(\Omega \mathrm{m})$ & \multicolumn{1}{c}{ Material } \\
\hline $1,25-5,67$ & Pasir \\
$5,67-55$ & Batu Pasir \\
$55-249$ & Lempung \\
\hline
\end{tabular}

Lintasan 2 diambil di kawasan UMP membentang mulai dari utara ke selatan sepanjang $195 \mathrm{~m}$ dengan kedalaman 39,2 m. Elevasi pada lintasan 2 sekitar 1,1\%. Lintasan 2 terletak pada koordinat $7^{\circ} 24^{\prime} 49^{\prime \prime}$ LS dan $109^{\circ} 16^{\prime} 19^{\prime \prime}$ BT; serta ketinggian 93 meter di atas permukaan laut (mdpl). Penampang dan nilai resistivitas dua dimensi lintasan 2 disajikan pada Gambar 4.

Berdasarkan Gambar 2, lapisan berwarna biru tua hingga biru muda diinterpretasikan sebagai lapisan airtanah dengan nilai resistivitas antara 16,2 - $77 \Omega \mathrm{m}$. Kedalaman akuifer bebas diperkirakan terletak pada kedalaman 3,75 25,9m bawah muka tanah (bmt). Kedalaman sumur di sekitar lintasan 2 sekitar $10 \mathrm{~m}$. Hasil interpretasi penampang dua dimensi lintasan 2

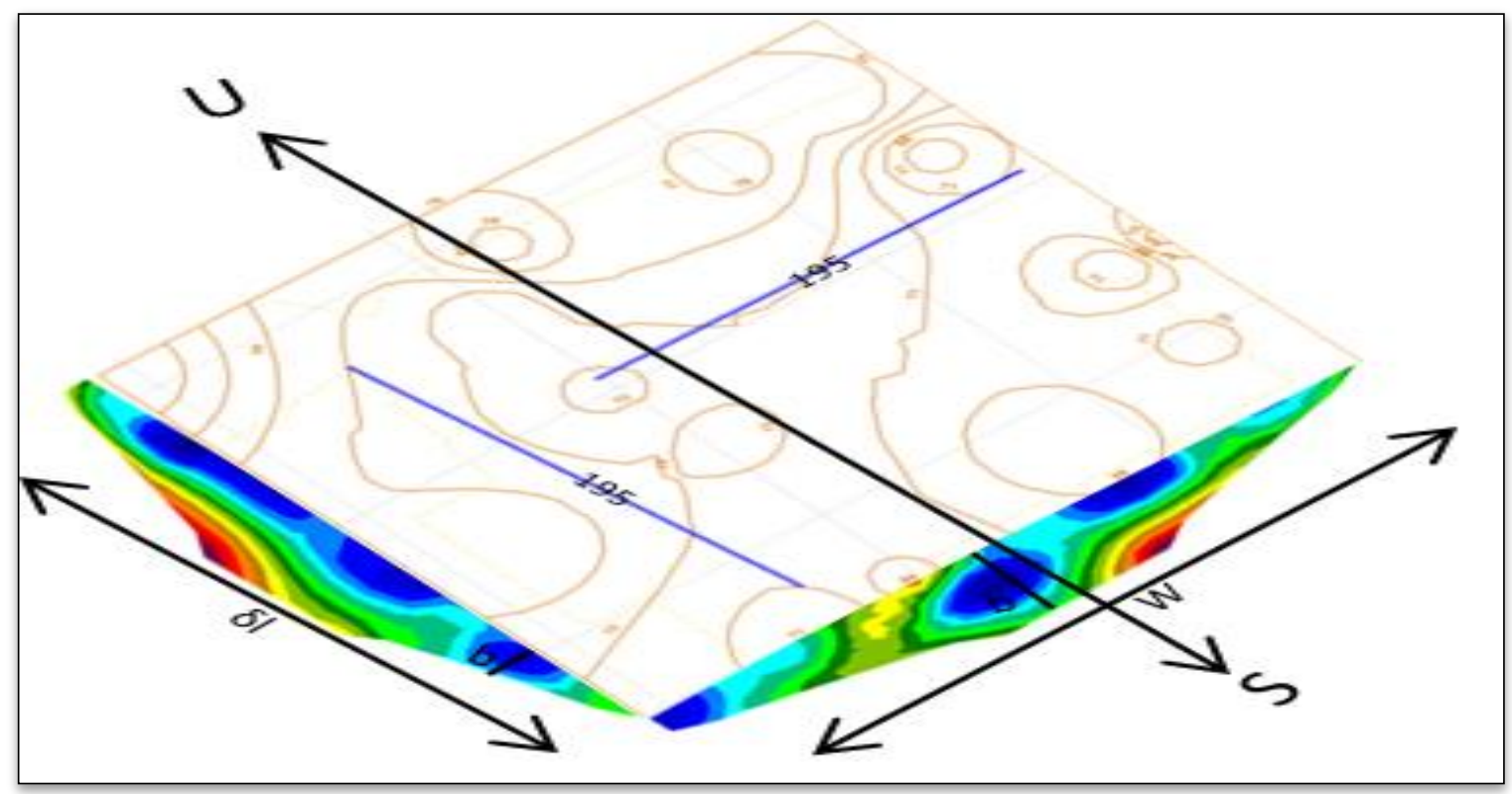

Gambar 2. Penampang Akuifer di Area Kampus Utama UMP

pada Gambar 1, diperoleh nilai resistivitas antara

pada Gambar 2, diperoleh nilai resistivitas antara $1,25-249 \Omega \mathrm{m}$. Berdasarkan klasifikasi Telford et 


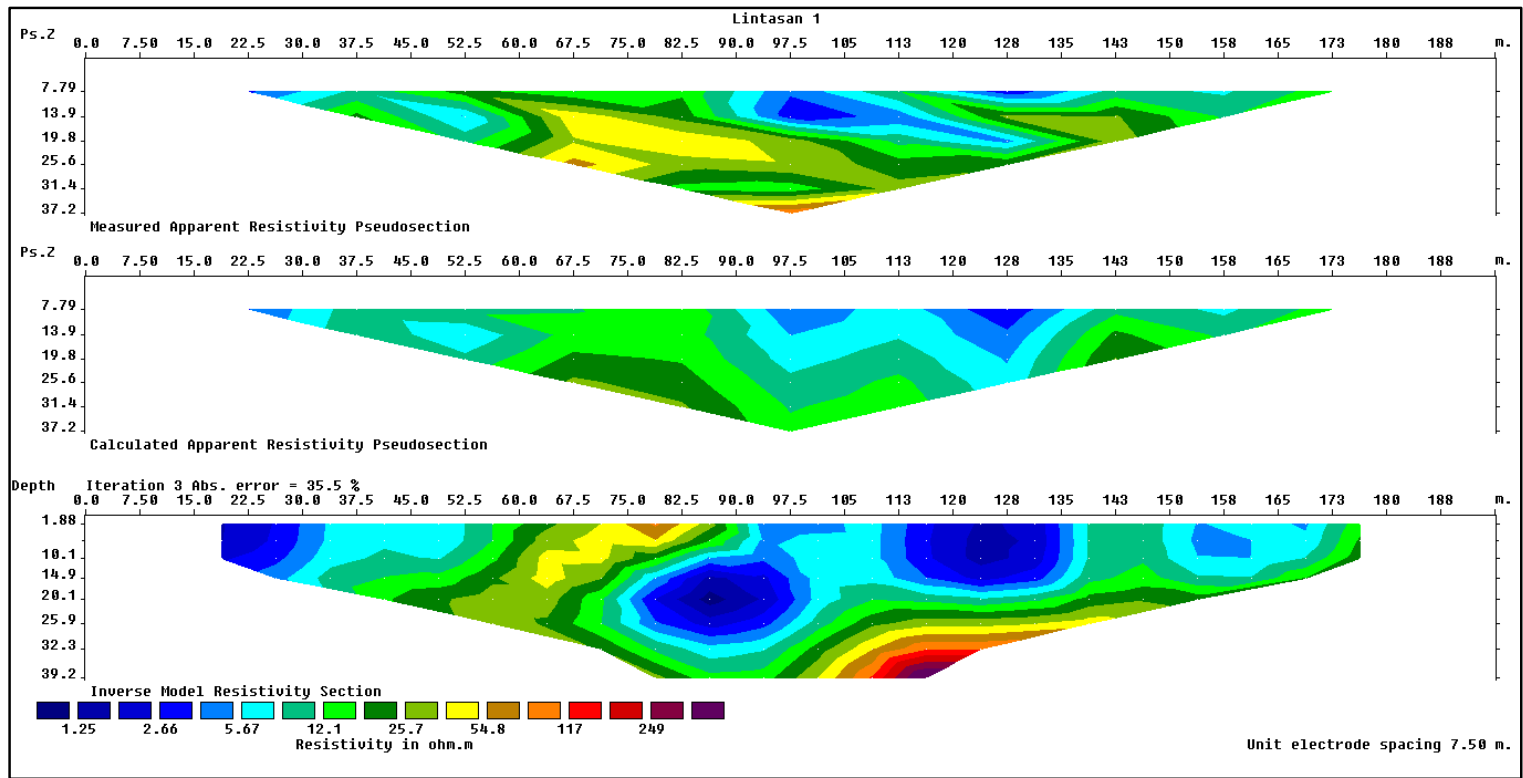

Gambar 3. Penampang dan Nilai Resistivitas Dua Dimensi pada Lintasan 1

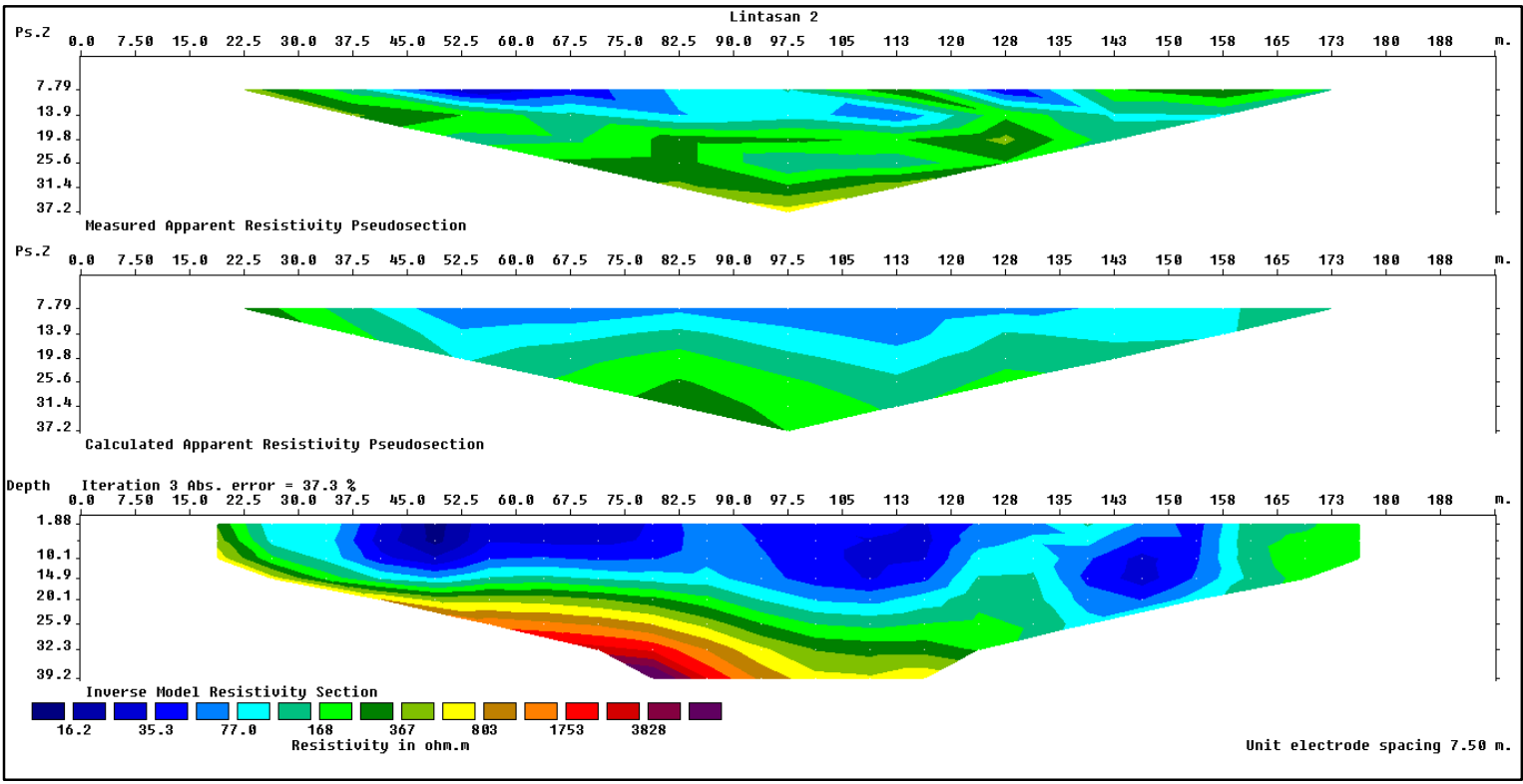

Gambar 4. Penampang dan Nilai Resistivitas Dua Dimensi pada Lintasan 2

$16,2-3.828 \Omega \mathrm{m}$. Berdasarkan klasifikasi Telford et al., (1990), jenis material yang terdapat pada lintasan 2 terdiri dari pasir, lempung, dan batu pasir (Tabel 3).

Persamaan Darcy digunakan dalam proses analisis data untuk menduga cadangan airtanah pada Lintasan 1 dan Lintasan 2. Nilai parameter persamaan Darcy didapatkan dari hasil analisis karakteristik akuifer di daerah penelitian. Konduktivitas hidrolik di kampus utama UMP berupa material pasir sedang, batu pasir pori-pori
Tabel 3. Nilai Resistivitas Material Lintasan 2

\begin{tabular}{cl}
\hline Nilai Resistivitas & \multicolumn{1}{c}{ Material } \\
$(\Omega \mathrm{m})$ & Pasir \\
$16,2-77$ & Batu Pasir \\
$77-803$ & Lempung \\
$803-3.828$ & \\
\hline
\end{tabular}

sedang, dan lempung, serta memiliki nilai konduktivitas hidrolik berturut-turut sebesar 12 $\mathrm{m} /$ hari, $0,0002 \mathrm{~m} /$ hari dan 3,1 $\mathrm{m} /$ hari dengan rata-rata 5,0334 $\mathrm{m} /$ hari. Nilai konduktivitas 
hidrolik dapat dilihat pada Tabel 4 (Todd dan Mays, 2005).

Tabel 4. Konduktivitas Hidrolik Beberapa Jenis Akuifer

\begin{tabular}{lc}
\hline \multicolumn{1}{c}{ Material } & $\begin{array}{c}\text { Konduktivitas } \\
\text { Hidrolik (m/hari) }\end{array}$ \\
\hline Pasir sedang & 12 \\
Lempung & 0,0002 \\
$\begin{array}{l}\text { Batu pasir pori-pori } \\
\text { sedang }\end{array}$ & 3,1 \\
\hline Rata-rata & 5,0334 \\
\hline
\end{tabular}

Tabel 5. Perhitungan Potensi Cadangan Airtanah di Kampus Utama UMP

\begin{tabular}{lcc}
\hline \multicolumn{1}{c}{ Parameter } & $\begin{array}{c}\text { Akuifer } \\
\text { Bebas }\end{array}$ & Satuan \\
\hline $\begin{array}{l}\text { Konduktivitas } \\
\text { hidraulik (K) }\end{array}$ & 5,0334 & $\mathrm{~m} / \mathrm{hari}$ \\
$\begin{array}{l}\text { Ketebalan lapisan } \\
\text { akuifer (b) }\end{array}$ & 29,1 & $\mathrm{~m}$ \\
$\begin{array}{l}\text { Panjang penampang } \\
\text { akuifer (W) }\end{array}$ & 156 & $\mathrm{~m}$ \\
$\begin{array}{l}\text { Beda kedalaman } \\
\text { muka Airtanah }(\delta \mathrm{h})\end{array}$ & 3 & $\mathrm{~m}$ \\
$\begin{array}{l}\text { Panjang lintasan } \\
\text { Airtanah }(\delta \mathrm{l})\end{array}$ & 195 & $\mathrm{~m}$ \\
\hline
\end{tabular}

Berdasarkan hasil perhitungan debit air (Q) menggunakan persamaan Darcy, diperoleh hasil perhitungan sebesar $351,53 \mathrm{~m}^{3} /$ hari atau 4,07 liter/detik. Berdasarkan perhitungan debit air tersebut, menurut Keputusan Menteri ESDM No.1451 K/10/MEM/2000 tentang kriteria klasifikasi debit airtanah, potensi cadangan airtanah di Kampus utama UMP termasuk dalam kriteria sedang (Tabel 6).

Tabel 6. Kriteria Klasifikasi Debit Airtanah

\begin{tabular}{cc} 
Kriteria & Besar debit \\
\hline Besar & $>10$ liter/detik \\
Sedang & $2-10$ liter/detik \\
Kecil & $<2$ liter/detik \\
\hline
\end{tabular}

Potensi cadangan airtanah di kawasan Kampus utama UMP termasuk dalam kriteria sedang menurut Keputusan Menteri ESDM No.1451 K/10/MEM/2000. Hal ini disebabkan oleh beberapa faktor yang mempengaruhinya. Faktor-faktor tersebut antara lain curah hujan, kondisi vegetasi, jenis akuifer, adanya sumur resapan, serta perbandingan luas bangunan dengan luas lahan terbuka hijau.

Berdasarkan sumber data dari Dinas Pengelolaan Sumber Daya Air Serayu Citanduy Kabupaten Banyumas tahun 2019, curah hujan yang terjadi di sekitar kampus utama UMP termasuk tinggi dengan rata-rata $3.180,75$ $\mathrm{mm} /$ tahun. Curah hujan yang tinggi tersebut berpotensi meningkatkan cadangan air tanah di kawasan Kampus utama UMP melalui proses infiltrasi ke dalam tanah. Tingginya curah hujan di kawasan Kampus utama UMP tersebut tidak serta merta menyebabkan tingginya potensi cadangan airtanah. Sebagian besar lahan terbuka di kawasan Kampus utama UMP telah berubah fungsi menjadi bangunan jalan, gedung dan perkantoran serta infrastruktur lainnya sehingga dapat menurunkan laju infiltrasi dan perkolasi. Hal ini sesuai dengan pendapat Abdulgani (2015), bahwa pembangunan fisik pada suatu lahan dapat menyebabkan berkurangnya area resapan yang mengakibatkan terjadinya penurunan laju infiltrasi dan bertambahnya run off.

Kondisi vegetasi pepohonan dan rumput di kampus utama UMP juga berpengaruh terhadap potensi cadangan airtanah. Jenis vegetasi yang terdapat di kampus utama UMP berupa tanaman keras dan rumput-rumputan. Jenis tanaman keras misalnya pohon Jati, Mahoni, Ketapang, Abasia dan Sengon. Jumlah vegetasi yang terdapat di Kampus utama UMP semakin berkurang akibat pohonnya banyak ditebang dan lahannya dialihfungsikan untuk bangunan fisik gedung. Padahal keberadaan poho-pohon tersebut dapat meningkatkan proses infiltrasi air hujan ke dalam tanah sehingga dapat meningkatkan jumlah cadangan air tanah. Menurut Arsyad (2006), penutupan tanah dengan vegetasi dapat meningkatkan laju infiltrasi suatu lahan. Dengan demikian dapat dikatakan bahwa kapasitas infiltrasi pada tanah bervegetasi akan cenderung lebih tinggi dibanding tanah yang tidak bervegetasi (Budianto et al., 2014). Lebih lanjut ditegaskan oleh Ardiansyah et al. (2019). bahwa lingkungan yang mempunyai vegetasi penutup bertipe pohon mempunyai kemampuan menyimpan air yang lebih baik.

Jenis akuifer tanah kawasan kampus utama UMP berupa lempung, pasir dan batu pasir. Tanah lempung memiliki sifat yang sulit untuk menyerap air sedangkan pasir memiliki ruang pori-pori yang besar sehingga kondisi tanah ini menjadi struktur yang lepas dan gembur. Dengan 
kondisi yang seperti itu menjadikan tanah pasir ini memiliki kemampuan yang rendah untuk dapat mengikat air (Asdak, 2010).

Faktor lain yang mempengaruhi potensi cadangan airtanah di kampus utama UMP yaitu adanya sumur resapan. Sumur resapan merupakan skema sumur atau lubang pada permukaan tanah yang dibuat untuk menampung air hujan agar dapat meresap ke dalam tanah. Keberadaan sumur resapan yang banyak dapat meningkatkan proses infiltrasi air hujan ke dalam tanah.

Perbandingan luas bangunan dengan luas lahan terbuka hijau di kampus utama UMP juga mempengaruhi cadangan airtanah di area tersebut. Hampir 52\% lahan di kampus utama UMP telah digunakan untuk bangunan dan jalan. Bangunan tersebut meliputi gedung perkantoran, ruang perkuliahan, perpustakaan, gedung auditorium, ruang laboratorium, ruang sekolah, sarana olah raga basket dan lapangan tenis. Sedangkan sisanya, 48\% lahan di kampus utama UMP berupa taman, lapangan bola, tanah kosong dan sarana olah raga bola voli. Dengan semakin luas lahan yang digunakan untuk bangunan, maka ketersediaan lahan terbuka hijau semakin sempit. Hal ini akan mempengaruhi jumlah air hujan yang masuk ke dalam tanah. Proses infiltrasi air hujan ke dalam tanah semakin berkurang, sedangkan proses run off air hujan semakin besar. Dampaknya, pada musim hujan di kawasan kampus ini sering terjadi banjir, sementara pada musim kemarau mengalami kekurangan air. Permasalahan ini sesuai dengan penrnyataan Nursetiawan dan Pratama (2017), bahwa permasalahan di wilayah perkotaan yang rutin terjadi pada saat hujan adalah terjadinya luapan air dan menimbulkan genangan ataupun banjir karena rendahnya resapan air ke dalam tanah. Namun sebaliknya, ketika musim kemarau sumber air banyak yang mengalami kekeringan karena cadangan air tanah permukaan yang ada habis disedot untuk keperluan rumah tangga dan industri.

\section{KESIMPULAN}

Hasil penelitian menunjukkan bahwa potensi cadangan airtanah di kampus utama UMP sebesar $351,53 \mathrm{~m}^{3} /$ hari atau 4,07 liter/detik. Menurut Keputusan Menteri ESDM No.1451 K/10/ MEM/2000, potensi cadangan airtanah di kampus utama UMP termasuk dalam kriteria "sedang".

\section{UCAPAN TERIMA KASIH}

Ucapan terima kasih penulis sampaikan kepada Lembaga Penelitian dan Pengabdian pada Masyarakat Universitas Muhammadiyah Purwokerto yang telah memberikan dana untuk kegiatan penelitian ini.

\section{DAFTAR PUSTAKA}

Abdulgani. H. (2015). Efektifitas Model Sistem Resapan Horizontal dengan Parit Infiltrasi dalam Mengurangi Limpasan Permukaan. Jurnal Rekayasa Infrastruktur, Vol. 1 (1): 36 - 43.

Ardiansyah, E.Y., T. Tibri, Lismawaty, A. Fitrah, S. Azan, J.A. Sembiring. (2019). Analisa Pengaruh Sifat Fisik Tanah Terhadap Laju Infiltrasi Air. Prosiding Seminar Nasional Teknik (SEMNASTEK) UISU: 8690.

Asdak, C. (2010). Hidrologi dan Pengelolaan Daerah Aliran Sungai. Yogyakarta: Gadjah Mada University Press.

Ashari, B., Darsono, dan Darmanto. (2014). Pemetaan Penyebaran Pola Akuifer dengan Metode Resistivitas Sounding Konfigurasi Schlumberger di Daerah Dayu Gondangrejo, Karanganyar. Indonesian Journal of Applied Physics, Vol. 04 (1): 70 - 77.

Arsyad, Sitanala. 2006. Konservasi Tanah dan Air. IPB Press, Bogor.

Budianto, P.T.H., R. Wirosoedarmo, dan B. Suharto. (2014). Perbedaan Laju Infiltrasi pada Lahan Hutan Tanaman Industri Pinus, Jati dan Mahoni. Jurnal Sumberdaya Alam dan Lingkungan, Vol. 1 (2): $15-24$.

Flathe, H. and W. Leibold . (1976). The Smooth Sounding Graph A Manual for Field Work in Direct Current Resistivity Sounding. Germany (DE): Federal Institute for Geosciences and Natural Resources.

Hatala, N. (2007). Model Matematis Perubahan Kualitas Air Sungai di Daerah Aliran Sungai (DAS) Cisadane. Institut Pertanian Bogor.

Karels, D.W. (2014). Model Spasial dan Faktor Pengontrol Akuifer Airtanah Dangkal Untuk Penentuan Zona Konservasi Airtanah di Kelurahan Oebufu Kota 
Kupang. Jurnal Teknik Pengairan, Vol. 5 (2):166 -171.

Mareta, N. (2015). Pola Aliran Sungai dan Kondisi Airtanah di Daerah Wado dan Sekitarnya: Untuk Perencanaan Kawasan Relokasi Baru. Pemaparan Hasil Penelitian Geoteknologi 2015 "Meningkatkan Kualitas dan Diseminasi Hasil Penelitian Melalui Pemberdayaan Kerjasama Ilmiah. Prosiding: $101-112$.

Maria, R., A.F. Rusydi, H. Lestiana, dan S. Wibawa. (2018). Hidrogeologi dan Potensi Cadangan Airtanah di Dataran Rendah Indramayu. Jurnal RISET Geologi dan Pertambangan, Vol. 28 (2): 181-192.

Nursetiawan dan A.I. Pratama. (2017). Pengukuran Nilai Infiltrasi Lapangan dalam Upaya Penerapan Sistem Drainase Berkelanjutan di Kampus UMY. RekaRacana: Jurnal Teknik Sipil, Vol. 3 (1): $14-25$.

Prasetya, D.A., R.S.B. Waspodo, dan S.K. Saptomo. (2016). Prediksi Cadangan Airtanah di Daerah Aliran Sungai (DAS) Cisadane. Jurnal Teknik Sipil dan Lingkungan, Vol. 1 (2): $59-68$.

Putri, M.A., et al. (2018). Sistem Aliran dan Potensi Air Tanah di Sebagian Desa
Sembungan Ditinjau dari Aspek Kualitas dan Kuantitas. Majalah Geografi Indonesia, Vol. 32 (2): 155 - 161.

Risanti, A. A., K.A. Cahyono, Latifah, M.A. Putri, dan N. Rahmawati. (2018). Hidrostratigrafi Akuifer dan Estimasi Potensi Airtanah Bebas Guna Mendukung Kebutuhan Air Domestik Desa Sembungan. Majalah Geografi Indonesia, Vol. 32 (1): 108-114.

Saputra, S.F.D., R.S.B. Waspodo dan B.I. Setiawan. (2016). Perhitungan Potensi Airtanah di Kecamatan Gabus Wetan, Kabupaten Indramayu, Jawa Barat. JSIL JURNAL TEKNIK SIPIL DAN LINGKUNGAN , Vol. 1 (3): 147-158.

Sumartoyo. (2010). Estimasi Potensi Airtanah Melalui Pendekatan Tipologi Bentuklahan Wilayah Bogor Provinsi Jawa Barat. (Landform Typological Approach To Estimate Groundwater Potency In Bogor Regency, West Java Province). Globë Vol. 12 (1): 57 - 67.

Telford, W.M., L.P. Geldart, R.E. Sheriff, and D.A. Keys. (1990), Applied Geophysics, Cambridge University Press - Science.

Todd, D.K. and L.W. Mays. (2005). Groundwater Hydrology. 3rd edition. John Wiley \& Sons, New York 